\title{
REVIEW \\ Glossiness of Leaf Blades in Sorghum (Sorghum bicolor L. Moench); Its Visual and Ultrastructural Studies
}

\author{
Isao TARUMOTO ${ }^{1 *}$ \\ Laboratory of Genetics and Plant Breeding, Graduate School of Agriculture and Biological Sciences, \\ Osaka Prefecture University (Sakai, Osaka 599-8231, Japan)
}

\begin{abstract}
The glossy leaf is an important character related with disease and pest resistance as well as varietal differences in Brassica oleracea and Zea mays. The author aimed to clarify the characteristic of glossiness that was newly found in sorghum cultivars. The visual difference between glossy and non-glossy plants could be identified by whether or not sprayed water adheres to leaf blades. The phenotype of non-glossy plants whose leaves shed water was due to the high density of star-shaped waxes that were detected in the ultrastructural observations. Moreover, true-glossy plants which water adheres to the surfaces of all leaves from 1st to flag leaf stages were found among Indian indigenous cultivars. The visual character of true-glossy plants was due to a reduction in the number of star-shaped waxes on leaves from 1 st to 5 th leaf stages in the observation by scanning electron microscope (SEM).
\end{abstract}

Discipline: Plant breeding / Genetic resources

Additional key words: Bloom, Brassica oleracea, glossy leaf, SEM, trichome, wax structure, Zea mays

\section{Introduction}

Sorghum (Sorghum bicolor L. Moench) originating in tropical Africa is a crop with extreme genetic diversity ${ }^{13}$. The genetic differentiation in the maturity was essential in the adaptation of sorghum to temperate environments for seed reproduction ${ }^{14,19}$. Sorghum is presently cultivated as a major crop in tropical and temperate countries such as India, China, USA, Australia, Argentina and Japan ${ }^{13}$ as well as Africa. The morphological variations in panicle, seed color, plant height, stalk sweetness and tillering capacity made sorghum possible to be used particularly as food and feed grain, forage grass, and for syrup and broom production ${ }^{13,15}$.

The glossiness expressed by the lack of epicuticular waxes on leaf blades was reported in recessive mutants of Brassica oleracea ${ }^{1}$ and Zea mays ${ }^{3,4}$. The glossiness has been generally used as a morphological marker in the breeding and genetic studies of the above two species, and the glossiness was reported to be related with the insect resistance in Brassica oleracea ${ }^{6,12}$ and with bacte- rial diseases in Zea mays ${ }^{11}$.

In sorghum, Ayyangar and Ponnaiya ${ }^{2}$ reported the bloomless sorghum that was lacking a bloom (wax) on the surfaces of leaf sheaths and stems, and Hanna et al. $(1974)^{8}$ revealed the relationship between bloomless plants and in vitro digestion by rumen fluid. However, no one reported the glossiness on leaf blades in sorghum. Therefore, the author studied the character expressions on glossy leaves in sorghum ${ }^{16-18}$. The present report deals with the phenotypes of glossiness in sorghum through visual and ultrastructural observations.

\section{Glossy and non-glossy plants}

The glossy mutants in Brassica oleracea and Zea mays were characterized in their shiny dark green leaves. They appeared glossy by the lack of a whitish bloom, which was attached on normal plants ${ }^{1,3,9}$. This characteristic was also confirmed by spraying water from a mist sprayer in the seedling stage ${ }^{1,3}$. When sprayed with a fine mist, leaves of glossy mutants retained water, whereas normal plants shed water. In broccoli (Brassica oleracea L. var. italica), the different characteristics between

\footnotetext{
Present address:

${ }^{1}$ (Tsukuba, Ibaraki 305-0051, Japan)

*Corresponding author: fax +81-029-855-1082; e-mail i_taru2002@ybb.ne.jp

Received 9 November 2004; accepted 9 December 2004.
} 


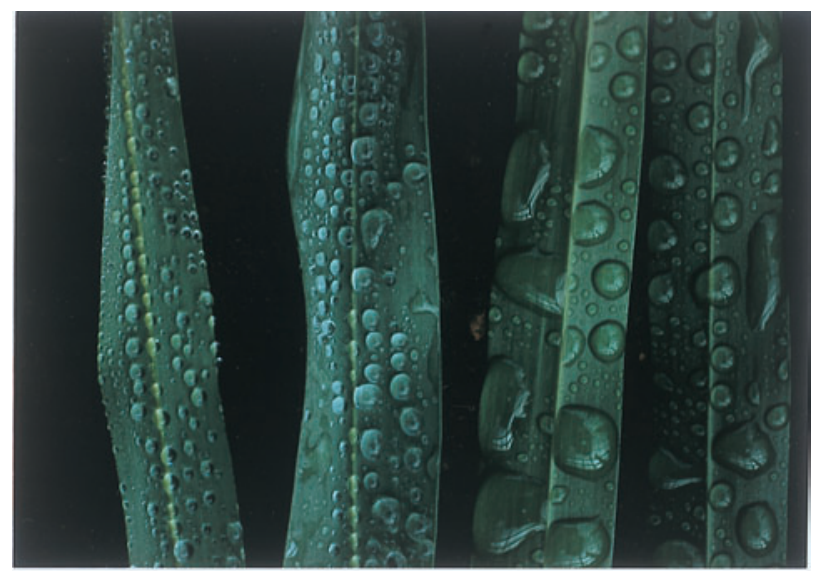

Fig. 1. Difference between shapes of droplets adhering to non-glossy leaves (left two) and glossy leaves (right two) when sprayed with water

glossy and normal plants remained throughout the life of the plant from the first true leaf ${ }^{1}$. While, in corn (Zea mays L.), the difference was expressed only in seedling stage until the 6th leaf stage and after that stage normal and glossy plants showed the same character for water to adhere in large droplets on leaf surfaces until flag leaf ${ }^{3,7}$.

In a rain or just after a shower, the author found the following trait in sorghum (Sorghum bicolor L. Moench); rare and small droplets adhering with water tension on the leaf surfaces of a cultivar, whereas water adhered either on all surfaces or in large and irregular shaped droplets on the leaf surfaces of certain other cultivars ${ }^{16}$ as illustrated in Fig. 1. The trait was considered to be similar with the glossiness in corn seedlings. Thus, the author conducted the character analysis of the above trait by visual and ultrastructural observation.

\section{(1) Character expression in visual observation}

Thirteen sorghum cultivars listed in Table 1 were seeded in the field on May 22, 1979, and were tested for their glossiness at five times between June 13 (4-5th leaf stage) and July 30 (flag leaf stage) by spraying water from a mist sprayer on leaf surfaces. The data were recorded in G (non-glossy leaf, on which water was shed or adhered in small droplets with water tension) or $\mathrm{g}$ (glossy leaf, on which water adhered in large and irregular shaped droplets) by the visible difference illustrated in Fig. 1. The relationship between leaf stages and character expression of glossiness are shown in Table 1. The glossiness of all tested cultivars remained $G$ until the 4 5th leaf stage (June 13). The glossiness of Sweet Sudan, Sudan GR-1 and Sendachi (F1: $390 \times$ Sweet Sudan) were classed into $G$ for all leaves from the first to flag leaf stages (July 30). While in the other 10 cultivars, the phenotype of $\mathrm{g}$ began to be defined in the leaves which

Table 1. The relationship between leaf stages and character expression of glossiness

\begin{tabular}{|c|c|c|c|c|c|c|c|c|c|c|}
\hline \multirow[t]{2}{*}{ Cultivars } & \multicolumn{2}{|c|}{ June $13(22)^{a)}$} & \multicolumn{2}{|c|}{ June 27 (36) } & \multicolumn{2}{|c|}{ July 5 (44) } & \multicolumn{2}{|c|}{ July 18 (57) } & \multicolumn{2}{|c|}{ July 30 (69) } \\
\hline & $\begin{array}{l}\text { Leaf } \\
\text { stage }\end{array}$ & Glossiness & $\begin{array}{l}\text { Leaf } \\
\text { stage }\end{array}$ & Glossiness & $\begin{array}{l}\text { Leaf } \\
\text { stage }\end{array}$ & Glossiness & $\begin{array}{l}\text { Leaf } \\
\text { stage }\end{array}$ & Glossiness & $\begin{array}{l}\text { Leaf } \\
\text { stage }\end{array}$ & Glossiness \\
\hline \multicolumn{11}{|l|}{ Grain sorghum: } \\
\hline bl CK-60 & 4 & G & 8 & g & 11 & g & 14.5 & $\mathrm{~g}$ & $17^{*}$ & g \\
\hline bmr-18 & 4.5 & G & 7.5 & g & 10 & g & 12.5 & g & 15.5 & g \\
\hline 605 & 4.5 & G & 8 & $\mathrm{~g}$ & 11 & $\mathrm{~g}$ & 15 & $\mathrm{~g}$ & $17^{*}$ & g \\
\hline 390 & 4 & G & 8.5 & g & 11 & $\mathrm{~g}$ & 14 & $\mathrm{~g}$ & $18^{*}$ & $\mathrm{~g}$ \\
\hline Regs. Hegari & 5 & G & 9 & g & 11.5 & g & 15.5 & g & $19 *$ & g \\
\hline Senkinshiro & 5.5 & G & 8.5 & g & 12 & $\mathrm{~g}$ & 15.5 & g & $17^{*}$ & g \\
\hline \multicolumn{11}{|l|}{ Sorgo: } \\
\hline Af. Millet & 5.5 & G & 9 & $\mathrm{~g}$ & 11 & $\mathrm{~g}$ & 14 & $\mathrm{~g}$ & 18 & $\mathrm{~g}$ \\
\hline Tracy & 4.5 & G & 8.5 & g & 11 & g & 14.5 & g & 17 & g \\
\hline \multicolumn{11}{|l|}{ Sudangrass: } \\
\hline GA337 & 4.5 & G & 8.5 & $\mathrm{~g}$ & 11.5 & $\mathrm{~g}$ & 14.5 & $\mathrm{~g}$ & $18^{*}$ & $\mathrm{~g}$ \\
\hline Sweet Sudan & 4 & G & 8 & G & 10 & G & 13.5 & G & $17 *$ & G \\
\hline Sudan GR-1 & 4 & G & 8 & G & 10.5 & G & 14 & G & $17^{*}$ & G \\
\hline \multicolumn{11}{|l|}{ Hybrid: } \\
\hline Sendachi & 5 & G & 9 & G & 11 & G & 15 & G & $19^{*}$ & G \\
\hline Hiromidori & 5 & G & 9.5 & g & 11.5 & $\mathrm{~g}$ & 15 & $\mathrm{~g}$ & 19 & g \\
\hline
\end{tabular}

a): Figures in parentheses show days after the seeding date (May 22).

* Flag leaf. 


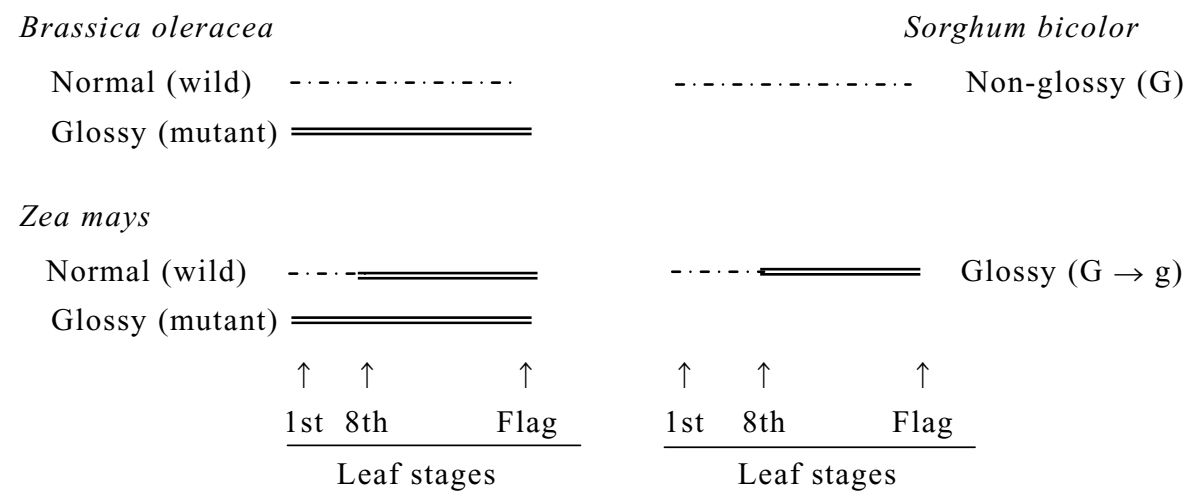

Fig. 2. The phenotypes and time of character expression of glossiness in Brassica oleracea, Zea mays and Sorghum bicolor

= : Water attached $(\mathrm{g}), \ldots \ldots \ldots$ : Water shed $(\mathrm{G})$.

Table 2. Glossiness, the distribution of waxes and the degree of trichome appearance on the adaxial surfaces of the $2 \mathrm{nd}, 5$ th and 11th leaves in sorghum cultivars examined

\begin{tabular}{|c|c|c|c|c|c|c|c|c|c|}
\hline \multirow[t]{2}{*}{ Cultivar } & \multicolumn{3}{|c|}{ 2nd leaf } & \multicolumn{3}{|c|}{ 5th leaf } & \multicolumn{3}{|c|}{ 11th leaf } \\
\hline & Glossiness ${ }^{\text {a) }}$ & $\mathrm{Wax}^{\mathrm{b})}$ & Trichome $^{\text {c) }}$ & Glossiness & Wax & Trichome & Glossiness & Wax & Trichome \\
\hline $\mathrm{SC} 112$ & $\mathrm{G}$ & 5 & 1 & $\mathrm{~g}$ & $3-4$ & 2 & $\mathrm{~g}$ & 3 & 3 \\
\hline Rancher & G & 5 & 1 & G & 5 & 2 & $\mathrm{~g}$ & $2-3$ & 3 \\
\hline Zairai-Tokin & $\mathrm{G}$ & 5 & 1 & G & 5 & 1 & G & 5 & 3 \\
\hline
\end{tabular}

a): G (non-glossy) and g (glossy) were classified by spraying water.

b): Figures show the degree of wax distribution on the leaf surface: 1 (less than 1\%), 2 (about 5\%), 3 (about 20\%), 4 (about 50\%), and 5 (more than $89 \%$ ).

c): Figures show the degree of trichome appearance on the leaf surface: 1 (absent), 2 (present rarely) and 3 (present frequently).

emerged after the 6th leaf stage, and the glossiness of the 10 cultivars was classed into $g$ after the 8-9th leaf stage (June 27) until flag leaf (July 30). These results ${ }^{16}$ suggest that the 8-9th leaf stage (approximately 35-40 days after seeding) would be the appropriate time for testing glossiness by the alternative classification of $\mathrm{G}$ or $\mathrm{g}$.

The color of non-glossy leaves that shed water was observed to be dull glaucous or whitish green, while the color of glossy leaves varied from shiny dark green to light green. The difference of leaf color is considered to be a pleiotropic effect of glossiness. The observation of leaf color after the 8-9th leaf stage would be usable to classify the glossiness instead of spraying water.

The characteristic of non-glossy plants in sorghum was the same as that of normal plants in broccoli (Brassica oleracea L. var. italica). The characteristic of glossy plants in sorghum was similar with that of normal plants in corn (Zea mays L.). The relationship among the above three species in glossiness is illustrated in Fig. 2.

(2) Ultrastructural observation

The glossy mutants in Brassica oleracea and Zea mays were characterized in their shiny dark green leaves. They appeared glossy by the lack of a whitish bloom, which was attached on the normal (non-glossy) plants ${ }^{1,3}$. In the observation of leaf surfaces using a scanning electron microscope (SEM), the non-glossy phenotype showed dense epicuticular waxes, while the glossy phenotype showed either no or sparse waxes ${ }^{6,9}$. The visual characteristics of non-glossy and glossy plants in sorghum corresponded to those in broccoli (Brassica oleracea L. var. italica) and corn (Zea mays L.). Thus, the ultrastructures of the surface of glossy and non-glossy leaves in sorghum were examined with a SEM to clarify the relationship between visual and ultrastructural appearances.

Three sorghum cultivars of SC112, Rancher and Zairai-Tokin were grown in a greenhouse. The 2 nd and 5 th leaves at 6 th leaf stage and the 11 th leaves at 12 th leaf stage were taken as the samples for SEM, and the glossiness of leaf blades were tested by spraying water at each sampling time. The samples were dehydrated in a graded ethanol series, placed into $100 \%$ iso-amyl acetate, and were finally dried in a critical-point dryer. The dried 
specimens were mounted on metal discs with silver conductive cement and were then coated with carbon and gold in a vacuum evaporator. Coated samples were examined with a Hitachi SEM (HHS-2R) at $15 \mathrm{kv}$ accelerating voltage.

Fig. 3 shows the ultrastructures on the adaxial surfaces of the 2 nd, 5 th and 11 th leaves of 3 cultivars examined. Table 2 shows the glossiness, the distribution of epicuticular waxes and the degree of trichomes on the adaxial surfaces of leaves mentioned above ${ }^{17}$. The 2 nd leaves of 3 cultivars, which were classified into $G$ (nonglossy), were covered with dense star-shaped epicuticular waxes (Fig. 3a-3d). The 5th leaves of Rancher and Zairai-Tokin, classified into $\mathrm{G}$, were covered with plentiful star-shaped epicuticular waxes, whereas the 5th leaves of SC112, classified into $g$ (glossy), bore no wax on the surface except for $1 / 4$ or $1 / 5$ of cells that bore sparse starshaped waxes (Fig. 3e-3g). The 11th leaves of SC112 and Rancher, classified into $\mathrm{g}$, bore no wax except for sparse long thread-shaped or irregular board-shaped waxes between cells arranged lengthwise (Fig. 3h and 3i). While the 11th leaves of Zairai-Tokin, classified into $\mathrm{G}$, were covered with dense star-shaped epicuticular waxes the same as in the 2nd and 5th leaves (Fig. 3j).

As mentioned above, in sorghum, the non-glossy plants showed high density of star-shaped waxes on leaves, whereas the glossy plants were characterized both by a reduction in the number of waxes and by different
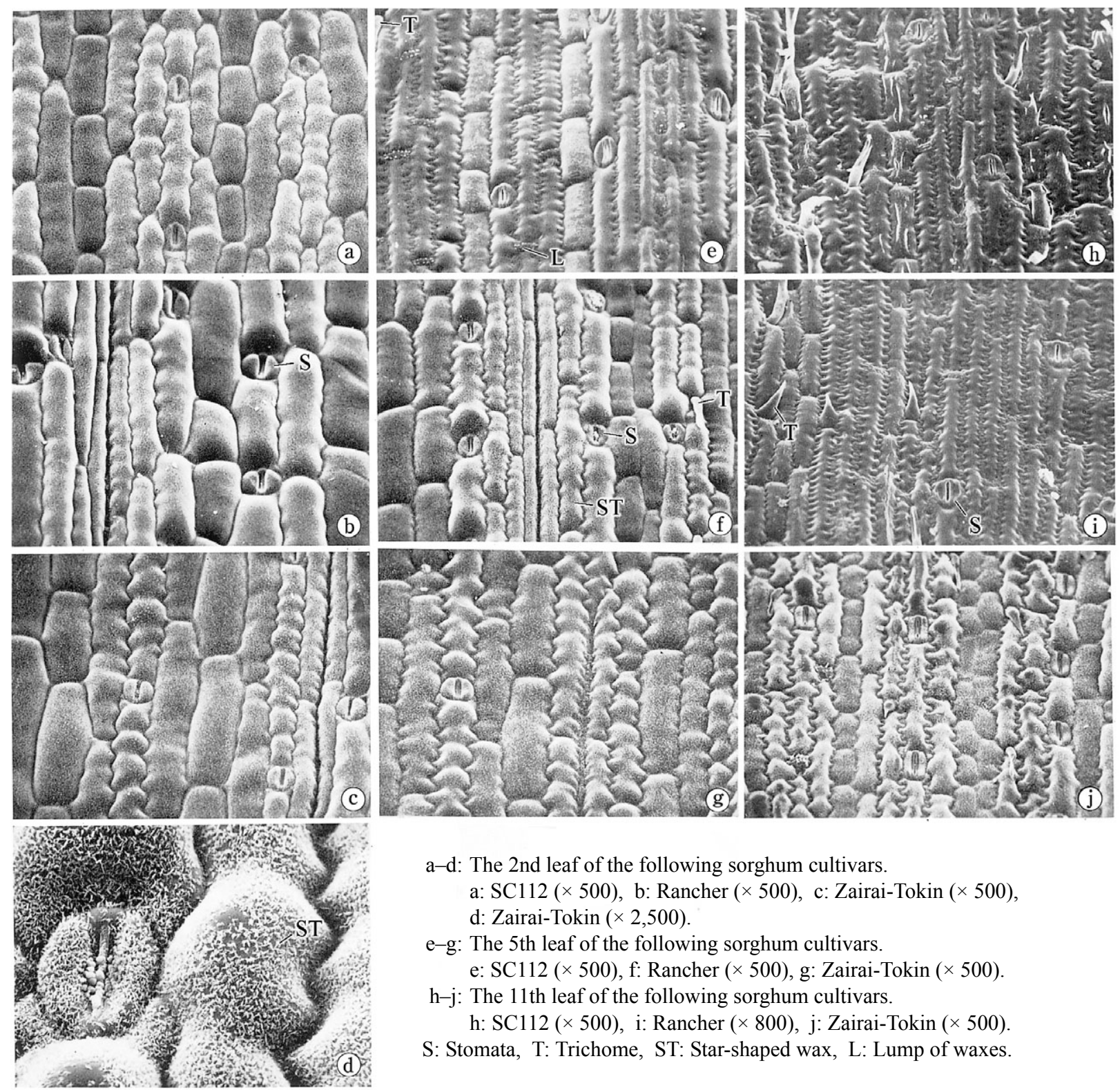

a-d: The 2nd leaf of the following sorghum cultivars.

a: SC112 $(\times 500)$, b: Rancher $(\times 500)$, c: Zairai-Tokin $(\times 500)$,

$\mathrm{d}$ : Zairai-Tokin $(\times 2,500)$.

e-g: The 5th leaf of the following sorghum cultivars.

e: SC112 (× 500), f: Rancher $(\times 500)$, g: Zairai-Tokin $(\times 500)$.

$\mathrm{h}-\mathrm{j}$ : The 11th leaf of the following sorghum cultivars.

h: SC112 $(\times 500)$, i: Rancher $(\times 800)$, j: Zairai-Tokin $(\times 500)$.

S: Stomata, T: Trichome, ST: Star-shaped wax, L: Lump of waxes.

Fig. 3. Scanning electron micrographs of the adaxial surfaces 
Table 3. Glossiness on the corresponding leaves classified by water spraying

\begin{tabular}{|c|c|c|c|c|c|c|c|c|c|}
\hline \multirow[t]{2}{*}{ Cultivars $^{\text {a) }}$} & \multicolumn{9}{|c|}{ Leaves at the following stage } \\
\hline & $1 \mathrm{st}$ & 2nd & $3 \mathrm{rd}$ & 4 th & 5 th & 6th & 7 th & 8 th & 9th-Flag \\
\hline IS1096, IS2147, IS4473 \& IS4637 & $\mathrm{g}$ & $\mathrm{g}$ & $\mathrm{g}$ & $\mathrm{g}$ & $\mathrm{g}$ & $\mathrm{g}$ & $\mathrm{g}$ & $\mathrm{g}$ & g \\
\hline IS4776, IS5567, IS5604 \& IS8962 & $\mathrm{g}$ & $\mathrm{g}$ & $\mathrm{g}$ & $\mathrm{g}$ & $\mathrm{g}$ & $\mathrm{g}$ & $\mathrm{g}$ & $\mathrm{g}$ & $\mathrm{g}$ \\
\hline IS4406, IS5642, IS6082 \& Swarna & G & G & G & G & G & $\mathrm{g}$ & g & $\mathrm{g}$ & $\mathrm{g}$ \\
\hline IS1314 & G & G & G & G & $\mathrm{G}$ & $\mathrm{G}$ & $\mathrm{g}$ & $\mathrm{g}$ & $\mathrm{g}$ \\
\hline $\mathrm{SC} 112$ & G & G & G & G & G & g & $\mathrm{g}$ & g & g \\
\hline Zairai-Tokin & $\mathrm{G}$ & $\mathrm{G}$ & $\mathrm{G}$ & $\mathrm{G}$ & $\mathrm{G}$ & $\mathrm{G}$ & $\mathrm{G}$ & $\mathrm{G}$ & $\mathrm{G}$ \\
\hline
\end{tabular}

a): The 13 cultivars of IS1096, IS1314, IS2147, IS4406, IS4473, IS4637, IS4776, IS5567, IS5604, IS5642, IS6082, IS8962, and Swarna were introduced from ICRISAT, India.

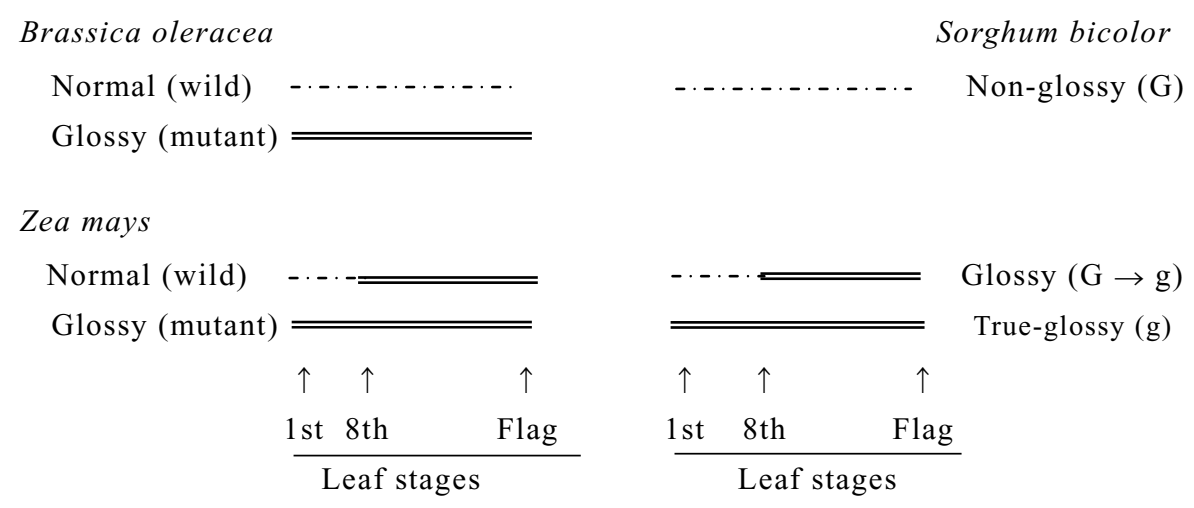

Fig. 4. The phenotypes and time of character expression of glossiness in Brassica oleracea, Zea mays and Sorghum bicolor : Water attached $(\mathrm{g}), \ldots \ldots \ldots \ldots$ : Water shed $(\mathrm{G})$.

shapes of waxes. In corn seedlings, the existence and/or quantity of epicuticular waxes on leaves observed by SEM were closely related with the visual difference of glossiness 9 . So the relationship between glossiness and density of epicuticular waxes on leaves in sorghum was almost the same as that in corn. Thus, the phenotype of non-glossy plants whose leaves shed water is considered to be expressed by the high density of star-shaped waxes, and the phenotype of glossy plants whose leaves had large irregular-shaped droplets adhering would be due to sparse waxes.

Blum $(1968)^{5}$ noted that trichomes sprouted on the leaf surfaces within the first seven leaves showed a mechanical resistance to sorghum shoot fly. In the present study, SC112 and Rancher, which were classified into g, bore trichomes on their 5th leaves, whereas ZairaiTokin that was classified into $G$ bore no trichomes on the 5 th leaves (Fig. $3 \mathrm{e}-3 \mathrm{~g})^{17}$. The results suggest a positive relationship between glossy plants and resistance to the sorghum shoot fly.

\section{True-glossy plants}

Maiti et al. (1984) ${ }^{10}$ studied the relationship between trichome development and resistance to sorghum shoot fly, and noted that the trichomed cultivars had the "glossy trait" which was characterized by having a glossy appearance during the first three weeks. While the glossy plants noted by Tarumoto $(1980)^{16}$ showed a non-glossy appearance until the 4-5th leaf stages (during the first three weeks in Japan). A discrepancy exists between the definitions of glossy trait by Tarumoto $(1980){ }^{16}$ and by Maiti et al. $(1984)^{10}$, suggesting that there would be some other types of glossiness in addition to glossy and non-glossy cultivars in sorghum. Thus, the author examined some Indian cultivars for their leaf characteristics that were related with the glossiness.

(1) Character expression in visual observation

The 15 cultivars listed in Table 3 were grown in a greenhouse and the glossiness was tested for leaf surfaces of the 1st to flag leaf by spraying water. According to the 

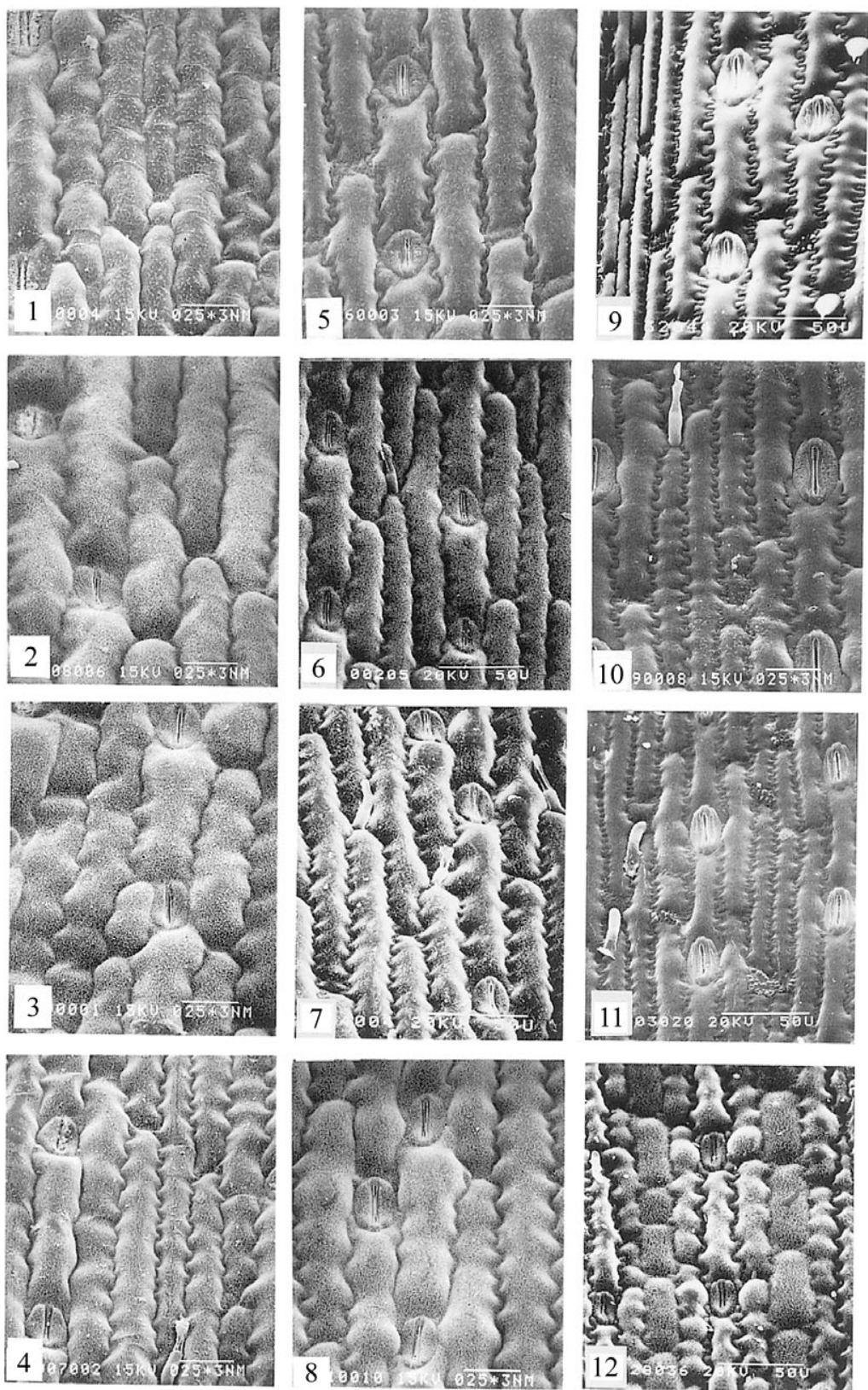

Fig. 5. Scanning electron micrographs of the adaxial surfaces of the 2nd, 4th and 8th leaves in "true-glossy", glossy and non-glossy cultivars

1-4: The 2 nd leaves of 1 (IS5604, × 800), 2 (IS1314, × 700), $3(\mathrm{SC} 112, \times 700), 4$ (Zairai-Tokin, $\times 800)$

5-8: The 4th leaves of 5 (IS5604, × 700), 6 (IS1314, × 600), 7 (SC112, $\times 700), 8$ (Zairai-Tokin, $\times 800)$.

9-12: The 8th leaves of 9 (IS5604, $\times 700), 10$ (IS1314, $\times 700)$, $11(\mathrm{SC} 112, \times 600), 12$ (Zairai-Tokin, $\times 600)$. 
criterion of Tarumoto $(1980)^{16}$, all 13 Indian cultivars and SC112 were classified into $g$ and Zairai-Tokin was classified into $\mathrm{G}$ after the 7 th leaf stage (Table 3$)^{18}$. However, the 8 cultivars of IS1096, IS2127, IS4473, IS4634, IS4776, IS5567, IS5604, and IS8962 were detected to have the same glossy appearance as corn glossy mutants, in which all leaves from the 1st to flag leaf have large and amorphous droplets adhering to their surfaces when sprayed with water ${ }^{3}$. The results ${ }^{18}$ showed that there were new types of cultivars for glossiness, true-glossy cultivars, in addition to glossy and non-glossy cultivars in sorghum. In addition to the characteristics of non-glossy and glossy plants in sorghum illustrated in Fig. 2, the characteristic of true-glossy plants in sorghum was defined to be similar with that of the glossy mutant in corn (Zea mays L.). The relationship is illustrated in Fig. 4.

\section{(2) Ultrastructural observation}

In order to clarify the differences between visual appearances of glossy and true-glossy plants, the 2 nd and 4th leaves taken at the 6th leaf stage and the 8th leaves taken at the 9th leaf stage of IS5604, IS1314, SC112, and Zairai-Tokin were subjected to ultrastructural examination through the procedures noted in Tarumoto et al. $(1981)^{17}$.

The 2nd and 4th leaves of IS1314 and SC112 (glossy cultivars) and Zairai-Tokin (non-glossy cultivar) were covered with dense star-shaped epicuticular waxes, whereas the 2nd and 4th leaves of IS5604 (true-glossy cultivar) bore sparse star-shaped epicuticular waxes (approximately 2-10\%). The 8th leaves of Zairai-Tokin were still covered with plentiful star-shaped epicuticular waxes, while the 8th leaves of IS5604, IS1314 and SC112 lost star-shaped epicuticular waxes and bore a small amount of amorphous wax particles (Fig. 5). From the results ${ }^{18}$, the relationship between the amount of starshaped waxes and the water repellency on leaf surfaces was clarified, and the distinctiveness of "true-glossy" cultivars in which all leaves from the 1st to flag leaf adhered water was demonstrated in terms of their ultrastructures.

\section{Conclusion}

The glossy leaf character was found in sorghum cultivars in addition to Brassica oleracea and Zea mays. The visual differences between glossy and non-glossy plants can be detected by whether or not sprayed water adheres to leaf blades. In the ultrastructural observations on the leaf surfaces of glossy and non-glossy sorghum plants using a SEM, the non-glossy plants showed a high density of star-shaped epicuticular waxes on all leaves from 1st to flag leaf, whereas the glossy plants were characterized by a reduction in the number of waxes and by different shaped waxes on leaves which appeared after the 6-8th leaf stages. Thus the phenotype of non-glossy plants whose leaves shed water was due to the high density of star-shaped waxes. Moreover, in Indian indigenous cultivars, true-glossy plants which water adhered to the surfaces of all leaves from 1st to flag were found. It was detected in the observation by SEM that the visual appearance of true-glossy plants was due to a reduction in the number of star-shaped waxes on leaves from 1st to 5th leaf stages in comparison with those of glossy plants. Consequently, the non-glossy plants in sorghum corresponded to normal (wild) plants in Brassica oleracea, the glossy plants in sorghum corresponded to normal (wild) plants in Zea mays and the true glossy plants in sorghum corresponded to glossy mutants in Brassica oleracea and Zea mays.

In Brassica oleracea and Zea mays, the inheritance and the pleiotropic effects of glossiness were studied and the glossiness became an important character for improving them. Thus, in sorghum, it is necessary to clarify this character in order to utilize the glossiness in breeding and genetic studies.

\section{References}

1. Anstey, T. H. \& Moore, J. F. (1949) Inheritance of glossy foliage and cream petals in green sprouting broccoli. $J$. Hered., 45, 39-41.

2. Ayyangar, G. N. R. \& Ponnaiya, B. W. X. (1941) The occurrence and inheritance of a bloomless sorghum. Curr. Sci., 10, 408-409.

3. Bianchi, A. \& Marchesi, G. (1960) The surface of the leaf in normal and glossy maize seedlings. Z. Vererbungle., 91, 214-219.

4. Borghi, B. \& Salamini, F. (1966) Analisi genetica di mutanti glossy di mais. I. Frequenze ai diversi loci. Maydica, 11, 45-57 [In Italian].

5. Blum, A. (1968) Anatomical phenomena in seedlings of sorghum varieties resistant to the sorghum shoot fly (Atherigona avria soccata). Crop Sci., 8, 388-391.

6. Eigenbrode, S. D. \& Kabalo, N. N. (1999) Effects of Brassica oleracea waxblooms on predation and attachment by Hippodamia convergens. Entomol. Exp. Appl., 91, 125-130.

7. Emerson, R. A., Beadle, G. W. \& Fraser, A. C. (1935) A summary of linkage studies in maize. Cornell Univ. Agric. Exp. Sta. Mem. 180.

8. Hanna, W. W., Monson, W. G. \& Burton, G. W. (1974) Leaf surface effects on in vitro digestion and transpiration in isogenic lines of sorghum and pearl millet. Crop Sci., 14, 837-838.

9. Lorenzonic, C. \& Salamini, F. (1975) Glossy mutants of maize. V. Morphology of the epicuticular waxes. Maydica, 20, 5-19 
10. Maiti, R. K. et al. (1984) The glossy trait in sorghum: Its characteristics and significance in crop improvement. Field Crops Res., 9, 279-289.

11. Marcell, L. M. \& Beattie, G. A. (2002) Effect of leaf surface waxes on leaf colonization by Pantoea agglomerans and Clavibacter michiganensis. Mol. Plant-Microbe Interactions. 15, 1236-1244.

12. Picoaga, A. et al. (2003) Resistance of kale populations to lepidopterous pests in northwestern Spain. J. Econ. Entomol., 96(1), 143-147.

13. Poehlman, J. M. (1979) Breeding Field Crops, Chap. 16. AVI Publishing Company, Inc., Westport, Connecticut, USA, 321-354.

14. Quinby, J. R. (1967) The maturity genes of sorghum. In Advances in Agronomy XIX, ed. Norman, A. G. Academic Press Inc., New York, 267-305.
15. Tarumoto, I. (1971) Studies on breeding forage sorghum by utilizing heterosis. Bul. Chugoku Nat. Agr. Exp. Sta., A19, 21-138.

16. Tarumoto, I. (1980) Inheritance of glossiness of leaf blades in sorghum, Sorghum bicolor (L.) Moench. Jpn. J. Breed., 30, 237-240.

17. Tarumoto, I., Miyazaki, M. \& Matsumura, T. (1981) Scanning electron microscopic study of the surfaces of glossy and non-glossy leaves in sorghum, Sorghum bicolor (L.) Moench. Bull. Natl. Grassl. Res. Inst., 18, $38-44$.

18. Tarumoto, I. (1986) Leaf characters of "true-glossy" cultivars detected in Indian local sorghums. Bull. Natl. Grassl. Res. Inst., 35, 42-46.

19. Tarumoto, I. et al. (2003) Inheritance of a thermo-sensitivity gene controlling flower initiation in sorghum. Breed. Sci. 53, 353-357. 